\title{
PENSANDO SOBRE A ESTRUTURA E ORGANIZAÇÃO DA RESENHA CRÍTICA
}

\author{
THINKING ABOUT THE STRUCTURE AND ORGANIZATION OF CRITICAL \\ REVIEW
}

Lidiomar José Mascarello ${ }^{1}$

\section{Resumo}

O artigo apresenta uma reflexão acerca dos conceitos de gêneros de discurso, e, a luz destes conceitos, uma análise de resenhas críticas disponibilizadas on-line. Para tanto, analisou-se, quatro resenhas publicadas e disponíveis em sites de revistas de educação e/ou de universidades federais. Pretende-se verificar se todos se utilizam adequadamente das habilidades linguísticas e conceituais que o gênero resenha crítica demanda. De acordo com diversos pesquisadores, a produção de gêneros escritos é uma atividade complexa que exige múltiplas capacidades e requer uma aprendizagem lenta e prolongada, que pode ser medida através da investigação dos textos de alunos. Nessa perspectiva, aderimos ao quadro teórico do Interacionismo Sociodiscursivo, ISD, em relação à caracterização dos gêneros e à metodologia de análise de textos. Foram consultados trabalhos de Bronckart (2006) sobre as atividades de linguagem, Baltar (2006) sobre conceitos de tipos de discurso, Schneuwly (1994) sobre gêneros orais e escritos, Bazerman (2007) sobre escrita e organização social, Swales e Askehave (2009) sobre identificação dos gêneros e os processos comunicativos e Bazerman (1993) sobre atos de fala, gêneros textuais e sistemas de atividades. Percebeu-se, ao observar as resenhas, que o uso da linguagem e o domínio dos processos de elaboração do gênero resenha capacita o estudante a executar práticas discursivas de leitura e de escrita que são requeridas a ele como membro da esfera acadêmica.

Palavras-chave: Resenha Crítica; Gêneros de discursos; Interacionismo Sociodiscursivo.

\begin{abstract}
This paper presents a reflection about the concept of discourse genres and follows them in the analysis of critical reviews published on websites. We have analyzed four reviews that were published in online magazines of federal Universities and/or in magazines about education. Our objective is to analyze if all of them use with adequacy the linguistic and conceptual abilities that the critical review genre demands. According to various researchers, the production of written genres is a complex activity that requires multiple capabilities and a long learning that can be measured by the investigation of students' texts. Thus we conform to the theoretical framework of the Social Discourse Interactionism in which concerns to the characterization of the genres and to the methodology in the analysis of texts. We have studied works about language activities by Bronckart (2006), about the concepts of the types of discourse by Baltar (2006), about oral and written genres by Schneuwly (1994), about writing and social organization by Bazerman (2007), about the identification of genres and the communicative processes by Swales e Askehave (2009) and about speech acts, textual genres and systems of activity by Bazerman (1993). As a result our observational study of the

\footnotetext{
${ }^{1}$ Doutorando do programa de Pós-Graduação em Linguística da Universidade Federal de Santa Catarina. E-mail: lidiomarjose@gmail.com.
} 
reviews, we have realized that the use of language and the controlling of the processes of elaboration of the review genre make the student capable of executing the discourse practices of writing and reading that are require in the academic sphere.

Keywords: Critical Review, Discourse Genres, Social Discourse Interactionism.

\section{Introdução}

Entra ano sai ano, entra governo sai governo, e, as especulações em torno da qualidade do ensino sempre se fazem presentes seja no âmbito político, social, histórico ou administrativo do país, evidenciando, assim, a necessidade de revisão e reestruturação dos processos de ensino/aprendizagem.

Nesse contexto os estudos sobre escrita de crianças e jovens, especialmente no Brasil, com base em teorias linguísticas, começaram a ser feitos no fim da década de 70 . Em decorrência disso, posteriormente, o trabalho com gêneros discursivos surge como uma alternativa viável e possível de ser adotada nesse processo transformando-se, posteriormente, em referência e diretriz nas questões concernentes ao ensino da Língua e a elaboração de propostas curriculares.

A apropriação da linguagem escrita acadêmica representa um desafio para os estudantes do ensino superior, devido às suas características peculiares tão distantes do universo escolar do ensino básico.

Para a elaboração deste trabalho procurou-se observar o que é definido como resenha crítica e quais são os elementos que constituem uma resenha crítica. Estes parâmetros de definição foram adotados a partir do Guia de Produção Textual da PUCRS; Do Guia Para Professores da Revista Infoescola, da Revista Recanto das Letras e principalmente da obra de Marconi, M. A. Lakatos, E. M. Fundamentos de Metodologia de 2003. Em seguida foi feita a seleção de quatro resenhas disponíveis on-line em sites de revistas de educação, sendo uma resenha de uma aluna do curso de Filosofia, denominada na análise de R1, outra de um trio de alunas do curso de Pedagogia, denominada na análise de R2, outra de uma aluna de mestrado em Linguística denominada na análise de R3, e, por fim, outra, de uma dupla de alunos, sendo um graduando em Letras e outro mestre na área de Educação, denominada na análise de R4. Não houve critérios específicos para a seleção das resenhas, pois o objetivo era apenas verificar se todos se utilizam das mesmas estruturas e regras de organização do gênero resenha e se efetivamente o que os Guias de Produção Textual e do Professor e o livro de 
metodologia acima citados é seguido, pois, tais guias apresentam regras do que se entende que é uma resenha e não um resumo, por exemplo.

No presente trabalho, o objetivo é discutir sobre a escrita de resenhas no Ensino Superior e Pós-Graduação, focalizando o uso das habilidades linguísticas e conceituais que o gênero resenha crítica demanda. Para tanto, apresenta-se na seção 2 os conceitos e principais características do gênero resenha. Na seção 2.1 faz-se uma reflexão acerca dos gêneros textuais e a resenha crítica. Na seção 3, analisa-se o domínio em produzir resenhas. Por último, reflete-se sobre as relações entre o conhecimento e o domínio do gênero resenha.

\section{Conceitos e características}

Resenha é uma descrição minuciosa que compreende certo número de fatos. Resenha crítica são a apresentação e análise do conteúdo de uma obra. Consiste na leitura, no resumo, na crítica e na formulação de um conceito de valor da obra resenhada feitos pelo resenhista (MARCONI, LAKATOS, 2003).

Segundo Machado (2005), a resenha acadêmica, como outros textos, realiza operações de linguagem, essas operações compreendem ações discursivas e linguístico-discursivas. Essas ações são representações do meio real dos sujeitos envolvidos nas situações comunicativas e os seus contextos socio-históricos que envolvem situação de produção e mobilização de conteúdos.

De acordo com o Guia de Produção Textual da PUCRS (2012); Do Guia Para Professores da Revista Infoescola e da Revista Recanto das Letras e principalmente da obra de Marconi, Lakatos, Fundamentos de Metodologia (2003), que tomamos como norteadores das definições das estruturas, o gênero resenha pode funcionar como um guia de leitura, podendo ser um texto em forma de síntese que expressa a opinião do autor sobre um determinado fato cultural, que pode ser um livro, um filme, peças teatrais, exposições, shows etc. O objetivo da resenha é guiar o leitor pelo emaranhado da produção cultural que cresce a cada dia. Ou seja, conforme esses guias, podemos encontrar diversos tipos de resenhas, tais como: resenha descritiva, resenha crítica e resenhas temáticas, dentre outros. Geralmente, no ambiente acadêmico, adota-se a resenha crítica, mas, independente de qual for a modalidade, a resenha, deve conter argumentos convincentes, elaborados a partir de conteúdos adequados e bem articulados. Sendo assim, no processo de ensino/aprendizagem da resenha, é indispensável que o estudante se instrumentalize de tal forma que seja capaz de desenvolver sua competência argumentativa. 
Os guias apresentam oito passos considerados importantes na escrita da resenha crítica acadêmica, ainda que sejam moldes bastante rígidos, responsáveis pela padronização dos textos científicos. Esses oito passos a seguir formam um guia para uma produção textual de uma resenha crítica completa: o primeiro é Identificar a obra, colocando os dados bibliográficos essenciais do livro ou artigo que será resenhado; o segundo é Identificar o autor, escrever brevemente sobre a vida e algumas outras obras do escritor ou pesquisador; terceiro Apresentar a obra, isto é, situar o leitor descrevendo em poucas linhas todo o conteúdo do texto que será resenhado; quarto Descrever a estrutura, ou seja, escrever sobre a divisão e organização da obra resenhada; quinto Descrever o conteúdo, em poucos parágrafos resumir claramente o texto resenhado; sexto Analisar de forma crítica, esse é o espaço para dar sua opinião. Argumentar baseando-se em teorias de outros autores, fazendo comparações ou até mesmo utilizando-se de explicações que foram dadas em aula; sétimo, Recomendar a obra, analisar para quem o texto realmente é útil (se for útil para alguém) e indicá-lo; e por fim, o oitavo passo Assinar e identificar-se: No último parágrafo você escreve seu nome e fala algo como "Acadêmico do Curso de Letras da Universidade Federal de Santa Catarina - UFSC”

\begin{tabular}{|l|l|}
\hline \multicolumn{3}{|c|}{ Estrutura da resenha } \\
\hline \multicolumn{2}{|c|}{ Título } \\
\hline Introdução & $\begin{array}{l}\text { Referência bibliográfica da obra, } \\
\text { (não deve ser o mesmo do objeto resenhado) } \\
\\
\text { comentário geral sobre a obra. }\end{array}$ \\
\hline Desenvolvimento & $\begin{array}{l}\text { Resumo breve da biografia do autor, } \\
\text { diretor ou compositor da obra resenhada. } \\
\text { Um resumo do conteúdo, sem entrar em } \\
\text { muitos detalhes. Uma avaliação crítica } \\
\text { com argumentos favoráveis e/ou } \\
\text { contrários. }\end{array}$ \\
\hline Conclusão & $\begin{array}{l}\text { Retomar os aspectos apresentados na } \\
\text { introdução e comentário geral. }\end{array}$ \\
\hline
\end{tabular}

Quadro 1: Organização geral da resenha. Com base em Marconi, e Lakato (2003).

Todos esses movimentos são operações discursivas que dizem respeito à estrutura textual, à organização sequencial e a sua articulação. Essa organização da resenha acadêmica, segundo Lima-Silva (2011, p.01) é uma forma de apresentação do "texto-fonte” e acontece pela predominância de sequências descritivas que servem de guia para o leitor.

Outra característica desse movimento é que, através do trabalho interpretativo, o resenhador "utiliza verbos que atribuem ao autor do texto fonte ações como: examina, classifica, analisa, comenta, propõe,” (LIMA-SILVA 2011, p.03). 
Além dos movimentos estruturais, existem as operações linguístico-discursivas que precisam ser levados em conta no momento da elaboração da resenha. Dentre essas operações destacamos os mecanismos de textualização (coesão e coerência, conexão entre as partes do texto, coerência nominal e verbal); mecanismos enunciativos, as modalizações e escolhas lexicais. Segundo Lima-Silva (2011, p. 04):

A coesão nominal ocorre na resenha pela repetição do nome completo do autor, de uma parte, pelo apagamento ou pela substituição 'o autor’, 'o pesquisador', etc. A coesão se dá também no referente à obra, através da indicação do título do livro no início e da retomada como 'a obra', o 'estudo', etc. No tocante aos mecanismos enunciativos, a resenha é constituída por ideias do resenhador e a do autor do texto-fonte, que são distinguidas com a utilização de expressões do tipo 'segundo x', seguido de paráfrase ou citação direta; uso de aspas ou aspas para termos técnicos utilizados pelo autor(es) do texto(s) resenhado; discurso direto destacado por aspas; discurso indireto, introduzido por verbos como 'diz que', 'sustenta que', etc. Podem ser utilizadas também expressões do tipo 'O livro apresenta...', 'O autor apresenta...', etc.

Todos estes mecanismos enunciativos ou de textualização contribuem para dar ao texto sua coerência linear ou temática, além da "heterogeneidade infra-estrutural" (BRONCKART, 2006, p. 148). Inferimos, com isso, que a resenha, ao mesmo, tempo informa sobre e avalia uma determinada obra, sendo que é a avaliação que define a resenha como resenha crítica. Para que ocorra esse processo de informação e avaliação de forma eficiente na comunidade acadêmica, o aluno/resenhista precisa articular bem e estabelecer claramente no seu texto o que são as ideias do autor ou autores da obra e as suas ideias enquanto resenhista.

\subsection{Além dos aspectos técnicos}

A resenha crítica utilizada na comunidade acadêmica é uma ação que se dá em um determinado tempo e lugar, que, segundo a perspectiva do interacionismo sociodiscursivo, esta ação ou o movimento de agir pode ser utilizado para “designar toda forma de intervenção de um ou vários seres humanos no mundo” (BALTAR, 2006, p. 145). No caso, trata-se de uma ação de domínio linguístico, que se estabelece como necessário: conhecer o contexto de circulação deste texto. No momento que o resenhista reordena, ou reescreve as informações de uma obra, ele ressignifica o conteúdo e estabelece novas relações com seu entorno.

Ao estabelecer novas relações com seu entorno, o resenhista cria condições para produzir novos conhecimentos a partir da operacionalização de uma ação comunicativa 
verbal, já que, segundo Bronckart (2006, p. 139), “os indivíduos singulares constituem-se em agentes da atividade”. Essa ação, que é proveniente do agir humano, se realiza em forma de texto mobilizando recursos lexicais e sintáticos de uma língua natural, por isso, segundo Bronckart (2006, p. 139), “os textos podem ser definidos como os correspondentes empíricos/linguísticos das atividades de linguagem de um grupo, e um texto como correspondente empírico/linguístico de uma determinada ação da linguagem,” que é o que ocorre com a resenha crítica. Ela mobiliza tanto aspectos empíricos cognitivos, já determinados pela esfera ou comunidade acadêmica, quanto aspectos lexicais, de escolha do resenhista, também sob influência das ações possíveis de serem realizadas no ambiente acadêmico.

Portanto, o agente que vai produzir um novo texto, isto é, que se encontra em uma situação de ação de linguagem precisa estar ciente das condições mínimas para realizar esta ação, que, de acordo com Bronckart (2006, p. 146), são: “a identificação do emissor, do espaço e tempo da produção [...], tipo de interação social em jogo, tanto para o emissor quanto para o receptor [...] e os conhecimentos disponíveis”.

Ao realizar este movimento de tentar compreender que tipo de interação social uma resenha crítica demanda, o resenhista precisa concomitantemente compreender os papéis dos diferentes discursos na sociedade contemporânea e os “nós de conexão” (SWALES, 2009) que os conteúdos da resenha podem estabelecer.

Para que os nós das conexões sejam feitos, desfeitos e refeitos é necessário que os sujeitos, resenhistas, apresentem um alto grau de letramento, isto é, capacidade de uso da escrita em diferentes contextos socioculturais, pois isto também é parte constituinte das ações e, segundo Bazerman (2007, p. 20), “o letramento é parte da coisa de que é feita a vida.”

\section{Análise do domínio de produção}

De acordo com Schneuwly (2004, p. 23), “o gênero é um instrumento”, em outras palavras, a resenha crítica é um instrumento e a capacidade de apropriação desse instrumento não é senão “o desenvolvimento das capacidades individuais correspondentes aos instrumentos materiais de produção. A apropriação de uma totalidade de instrumentos de produção é o desenvolvimento de uma totalidade de capacidades nos próprios indivíduos” (MAX e ENGELS apud SCHNEUWLY 2004, p. 23).

Veremos a seguir como cada um dos resenhistas se apropriou dos instrumentos necessários na elaboração de suas resenhas. 
O primeiro aspecto a ser analisado é em relação à estrutura da resenha: o primeiro passo é identificar a obra, referência bibliográfica da obra, conforme ABNT e comentário geral sobre o autor e a obra.

R1

Theodor Adorno nasceu em 11 de Setembro de 1903, em Frankfurt, doutorou-se na Universidade de Frankfurt ao apresentar a tese: A transcendência da coisa e do nomeático na fenomenologia de Husserl. Ficou conhecido por sua obra Dialética do Esclarecimento, escrita juntamente com Horkheimer na qual cunharam o famoso conceito de Indústria Cultural. Educação após Auschwitz foi uma palestra transmitida na rádio de Hessen, em 18 de abril de 1965, publicada em Zum Bildungsbegriff der Gegenwart, em Frankfurt, no ano de 1967. Filósofo da Escola de Frankfurt, adepto da Teoria Crítica, traz-nos em Educação após Auschwitz a questão da barbárie humana. O próprio nome do texto faz referencia direta ao principal campo de concentração da Alemanha Nazista, a saber, Auschwitz.

R2

A presente resenha do livro de Moretto, (2007) em sua $2^{\circ}$ edição tem o intuito de mostrar que a avaliação é um processo que nos faz refletir sobre o instrumento mais utilizado no contexto educacional que é a prova. O autor traz um novo significado para a avaliação, discute que ela deve ser inserida de uma forma diferente, em que predomine a clareza nos objetivos e nas formas de se avaliar, de modo que seja mais justa permitindo que o aluno aprenda de uma forma mais significativa.

R3

Como promover a leitura literária em sala de aula? Como formar alunos leitores? Como fazer com que os alunos compreendam o que leem? Por que os alunos não gostam de ler? São muitas as questões levantadas pelos professores acerca da leitura em sala de aula, já que um dos principais desafios do magistério reside justamente nas dificuldades encontradas nas aulas de leitura. Como promover a leitura literária em mundo em que as novas tecnologias como internet, televisão, celular competem e dividem a atenção e o interesse dos alunos? São essas e outras questões que Rildo Cosson tenta responder em seu livro Letramento literário: teoria e prática.

R4

\section{A ARTE DE ENSINAR DE WOLFGANG RATKE (1571-1635)}

Wolfgang Ratke (1571-1635) nasceu na província de Holstein e a sua juventude em hanseática de Hamburgo, onde se firmou como membro da burguesia e sua posição política. Estudou teologia, filosofia, línguas orientais e matemática, na Universidade de Rostock. Para Sandino Hoff, apresentador e tradutor da obra, os textos pedagógicos de Wolfgang Ratke são de grande relevância para a história da educação. As suas propostas e práticas educacionais expressam o pensamento pedagógico dos Tempos Modernos, sobretudo, os ideais da pedagogia humanista do século XVI e sua preocupação e o cuidado do bem educar dedicado às crianças. O trabalho pedagógico Ratke à renovação da instituição escolar e a didática, no contexto alemão de sua época, inaugurou as novas bases da pedagogia moderna, envolvendo a organização do trabalho didático e, a retomada do 
estudo de suas obras no século XIX, coincidiu com a constituição dos sistemas nacionais de ensino e, na Alemanha, com a unificação política.

Como podemos observar, apenas R1 e R4 seguem as regras ou normas de identificação da obra resenhada e do(s) autor(es) pré-estabelecidas como necessária para que se constitua uma resenha crítica. R3 sequer cita o nome da obra e do autor da mesma. R2 cita apenas o autor e a data, mas não cita a obra. Seriam estas regras desnecessárias? Ou seria um não domínio do sujeito sobre o objeto ao qual ele deve agir?

Na perspectiva da interação, segundo Schneuwly (2004), em que se admite que a ação do sujeito é mediada por objetos específicos, socialmente elaborados e que são frutos das experiências anteriores e que os instrumentos servem de mediação da ação dos sujeitos, o que se constata em R2 e R3 é que parece não haver domínio dos instrumentos necessários para atender as demandas de uma resenha crítica acadêmica, embora seja possível também tratar-se de um estilo individual de autoria possibilitada pela instabilidade ou permissividade que o gênero resenha crítica permite.

Outro passo importante é apresentar a obra, isto é, situar o leitor, descrevendo em poucas linhas todo o conteúdo do texto que será resenhado, descrever a estrutura, ou seja, escrever sobre a divisão e organização da obra resenhada; descrever o conteúdo, em poucos parágrafos resumir claramente o texto resenhado:

R1

Em Educação após Auschwitz, o filósofo nos diz de maneira bastante clara e neste momento faz alusão aos estudos de Freud, que na própria gênese da civilização está contida a barbárie. Durante todo o seu texto, Adorno nos tenta mostrar de que forma esta barbárie humana poderia ser amenizada. O que seria o nazismo se não a expressão mais profunda da barbárie a que nós, seres humanos, podemos chegar? Para o autor, reside aí a importância fundamental da educação: impedir o retorno à barbárie, impedir que Auschwitz se repita.

R2

Nessa obra o autor traz vários exemplos de como estruturar uma avaliação que corresponda a: faixa etária do aluno, ao contexto social em que o aluno está inserido e ao modo correto de se avaliar este aluno respeitando o processo que o aluno faz para construir seu próprio conhecimento. Além de nos mostrar que é possível avaliar bem a aprendizagem mantendo a cultura da aplicação de provas, desde que o processo seja ressignificado e contextualizado.

R3

Com um enfoque claro no ensino de literatura na escola básica, Cosson escreve um livro de professor para professores no intuito de promover o 
letramento literário no que se refere ao processo de escolarização da literatura. A obra se divide em três momentos: nos pressupostos, o autor discute o valor social da literatura, sua escolarização e analisa o processo de leitura à luz de suas várias teorias. No segundo momento, o autor apresenta práticas do letramento literário, em sala de aula, com exemplos de uma sequência didática básica e uma sequência expandida e, por fim, apresenta diversas oficinas com o objetivo de fornecer ao professor mais ferramentas para um trabalho profícuo.

R4

A obra "Escritos sobre A Nova Arte de Ensinar de Wolfgang Ratke (15711635): textos escolhidos” é organizada em quinze capítulos. Nela, compreende-se que os objetivos de Ratke são articulados a três dimensões: as funções do Estado, a organização da escola e a arte de ensinar. A obra é composta da seguinte maneira: Capítulo 1: Memorial; Capítulo 2: Método Geral da Didática ou da Arte de Ensinar de Wolfgang Ratke (1613-1614); Capítulo 3: Artigos nos quais se baseia especificamente a arte de ensinar de Wolfgang Ratke (1616); Capítulo 4: Alguns pontos nos quais se baseia solidamente a didática ou a arte de ensinar de Wolfgang Ratke (1618); Capítulo 5: Regulamentação do horário escolar para a nova arte de ensinar de Wolfgang Ratke (1619); Capítulo 6: O método da arte de ensinar de Wolfgang Ratke (1620-1622); Capítulo 7: Breve contato com a grande utilidade da arte de ensinar (1622-1633); Capítulo 8: Tonel de Ratke feito rolar, cortesmente, até todos os soberanos e todas as autoridades da nação alemã (1626); Capítulo 9: A constituição geral das escolas cristãs, que deve ser confirmada e mantida na verdadeira harmonia da fé, da natureza e das línguas, a partir da sagrada escritura divina, da natureza e das línguas, para a arte de ensinar de Ratke (1626-1630); Capítulo 10: Registro de todos os ensinamentos tirados da escritura santa, da natureza e das línguas, em harmonia verdadeira com a fé, a natureza e as línguas (1626-1630); Capítulo 11: A arte de ensinar das escolas cristãs organizada na harmonia da verdadeira fé, da natureza e das línguas, confirmada e mantida a partir da natureza e das línguas; Capítulo 12: Tratado das funções do soberano conforme a escola cristã, que deve ser organizada, confirmada e mantida a partir da escritura santa, da natureza e das línguas, na harmonia verdadeira da fé, natureza e das línguas para a arte de ensinar de Ratke (1631); Capítulo 13: Tratado sobre a administração escolar (Scholastica Schuldieneramtslehre) (1631-1632); Capítulo 14: Manuscritos da ratichiana gothana, manuais escolares, manual de geografia (Specimen Compendii Geographiae - em Alemão) e, por último, Capítulo 15: A arte da gramática.

Podemos observar que em relação à descrição da organização da obra e o que é efetivamente abordado nela, apenas R4 consegue realizar de forma adequada. R2 e R3 em nenhum momento citaram, no corpo do texto, o nome da obra resenhada. R1 descreve de forma mais sucinta os aspectos mais relevantes da obra, mas não fica claro se a pergunta aí colocada é do autor da obra ou é do resenhista. Há uma ambiguidade de autoria de ideias, não deixando claro para o leitor quais são os limites entre o texto-fonte e as possíveis opiniões do resenhista. 
Como terceiro movimento de observação e análise, verificamos que a resenha crítica deve contemplar: análise de forma crítica, recomendar a obra, assinar e identificar-se:

R1

R2

Percebemos claramente que Adorno, em suas reflexões sobre Educação após Auschwitz, faz uso constante da psicanálise e um dos aspectos importantes que o autor ressalta, em seu texto, é a questão da consciência coisificada. Para ele, alguns seres humanos chegaram a tal ponto de frieza em todas suas relações, ao preferirem a companhia das máquinas em detrimento dos seres humanos e equipararem os próprios seres humanos a coisas.

Outro conteúdo apresentado pelos autores que deve ser trabalhado durante o processo de aprendizagem são os conteúdos procedimentais. No entanto por serem atividades repetitivas destinadas a fixação, para Moretto deve nos ater a duas condições antes de utilizá-las como instrumento avaliativo. Em primeiro lugar o aluno tem que ter um conceito correto dos objetivos de conhecimento e saber os procedimentos pelos qual o leva a situações complexas. Nestes conteúdos por sua vez é levado em conta o saber fazer, o raciocínio, ou seja, o professor dá relevância ao "caminho" (percurso) pelo qual o aluno fez para chegar a determinado resultado. $O$ último dos conteúdos apresentados por eles são os conteúdos atitudinais, que têm por objetivo a formação para os valores, como o respeito, a responsabilidade, a honestidade, a formação das atitudes. Os conteúdos atitudinais são trabalhados no contexto dos outros conteúdos no processo de ensino.

[...] Sendo assim este livro é de grande relevância para estudantes de licenciatura, mostrando a como avaliar da forma mais correta e justa, não deixando de lado o uso dos conteúdos, mas dando um novo significado a avaliação. O mesmo vale para os professores, porém como cada um tem seu modo de atuar, este livro vem com a intenção de fazer o professor refletir sobre sua postura e até mesmo métodos que utiliza em sala de aula, planejando suas aulas da melhor forma possível. É importante também que alunos saibam o objetivo do livro e possam reivindicar por melhores aulas e expor sua opinião sobre a clareza de determinada questão. Os pais também deveriam ler este livro, com o intuito de conhecerem melhor o processo da avaliação e junto com o professor de seus filhos discutirem as dificuldades dos alunos e ir propondo novos caminhos para a melhoria no ensino.

R3

Assim, no letramento literário não podemos simplesmente exigir que o aluno leia a obra e ao final faça uma prova ou ficha, pois a leitura é construída a partir dos mecanismos que a escola desenvolve para a proficiência da leitura literária. O autor, na construção de seus pressupostos teóricos, trabalha com teorias linguísticas sobre o processamento sociocognitivo da leitura, discutindo questões importantes como a decodificação, interpretação, construção de sentido de um texto. Após a breve apresentação teórica, Cosson mostra as quatro etapas da sequência básica: a motivação que consiste na preparação do aluno para que ele "entre" no texto. Normalmente, essa etapa se dá de forma lúdica, com uma temática relacionada ao texto literário que será lido e tem como objetivo principal incitar a leitura proposta.

[...]Tais características fazem de Letramento Literário: teoria e prática um livro de leitura obrigatória não só para aqueles que pretendem trabalhar com 
o texto literário na escola, mas também para os professores interessados em fazer da escola um lugar no qual seja possível formar cidadãos que sejam leitores críticos de todo e qualquer gênero textual.

R4

[...] Wolfgang Ratke é uma importante referência da história da educação, imprescindível aos estudiosos do campo educacional, pelo rigor e clareza de seu método de ensino. O seu trabalho, a "nova arte de ensinar" é anterior a Comenius e sua didática de "ensinar por meio de todas as coisas a todos os homens". Desse modo, em seu pensamento social e educacional, a organização administrativa e pedagógica do ensino pelo Estado e a arte de ensinar são temas fundamentais em seus textos. A política também figura entre eles, já que defendeu entre os soberanos de sua época, a construção de prédios escolares, o seu método, a preparação de professores e a implementação de sua arte de ensinar.

Em R1 percebe-se que há uma análise de forma crítica e uma intertextualidade com outras perspectivas teóricas, mas não há recomendação da obra para outros leitores e nem há uma assinatura.

Em R2 percebe-se tanto uma postura crítica quanto a recomendação tanto para pais, alunos e professores.

Em R3 também se percebe tanto uma postura crítica, ainda que, às vezes, a voz do autor da obra e a voz do resenhista não sejam muito fáceis de serem diferenciadas, quanto uma preocupação em indicar a obra para diferentes leitores.

Em R4 percebe-se uma grande preocupação com o conteúdo da obra, ou seja, o textofonte e há pouca manifestação do resenhista e não há uma indicação da obra para leitura.

Em relação à assinatura no final do texto, nenhuma das quatro resenhas analisadas apresentou uma assinatura.

Em síntese, ao analisar as quatro produções podemos verificar que não é o fato de existirem guias ou padrões a serem seguidos que efetivamente se têm produções homogêneas (enquanto estrutura), dadas as muitas variáveis que interferem na produção de um texto acadêmico.

\section{Como ensinar o aluno a escrever uma resenha}

Simples, o estudante deve $1^{\circ}$ Identificar a obra, $2^{\circ}$ Identificar o autor, $3^{\circ}$ Apresentar $a$ obra, $4^{\circ}$ Descrever a estrutura, $5^{\circ}$ Descrever o conteúdo, $6^{\circ}$ Analisar de forma crítica, $7^{\circ}$ Recomendar a obra, $8^{\circ}$ Assinar e identificar-se. Não, definitivamente escrever não é algo 
como seguir os passos de uma receita culinária em que basta colocar adequadamente os ingredientes e o resultado final será o esperado. Como podemos perceber nos dados analisados, o resultado não é o mesmo para todos. Constata-se, portanto, que não há uma receita pronta, mas existem mecanismos que precisam ser levados em consideração.

Em primeiro lugar, é importante que o professor, ao orientar um trabalho de resenha ou ao solicitar ao aluno que escreva uma resenha, verifique se este aluno já escreveu uma resenha antes e, além disso, mostrar aos alunos que existem diferenças entre resenha, resenha crítica e resumo de uma obra. É necessário que o professor apresente aos alunos várias resenhas, de preferência de diferentes áreas do conhecimento, para que estes percebam a existência de movimentos concatenados e não aleatórios que garantem uma estrutura ou arquitetura do texto, mas mais do que apresentar é preciso exercitar, isto é, o aluno precisa escrever, precisa treinar.

Em segundo lugar, mas não menos importante, os alunos precisam dar-se conta que um bom texto, mais do que conhecer os aspectos técnicos, depende do conhecimento e do domínio da informação. Ninguém consegue falar ou escrever bem sobre algo que desconhece. E como aqui se discute o gênero resenha crítica na universidade, acredita-se na autonomia e na busca individual do conhecimento, ainda que em alguns momentos guiada.

Este segundo ponto é difícil de ser medido e depende da trajetória de cada indivíduo, de cada estudante, por isso, é importante que o professor conheça a realidade em que atua para poder propiciar meios adequados a cada um. E, por conta disso, não podemos garantir resultados homogêneos (em termos de estrutura, não de conteúdo) e totalmente satisfatórios em qualquer que seja o gênero textual adotado, mas é possível a cada leitura e releitura garantir construção de significados.

\section{Considerações finais}

Considerando que toda resenha é, de certa forma, uma descrição detalhada a respeito de determinado conjunto de fatos, sejam eles relatados em uma obra como, por exemplo, um livro, um filme, um artigo científico ou outros, o resenhista deve possuir a capacidade de fazer uma releitura e atribuir significados a sua ação.

De acordo com o que observamos, ao analisar as resenhas e tendo em vista as características do gênero resenha crítica, percebe-se que é necessário insistir no desenvolvimento dos acadêmicos e instrumentalizá-los para que se tornem agentes de seu processo de formação acadêmico. Para tanto, é necessário focalizar as habilidades 
relacionadas à intertextualidade e a capacidade de argumentação. Como produtor de gêneros acadêmicos, o estudante precisa ser motivado a ter objetivos e a realizar seus projetos de ter o que dizer e de desenvolver a capacidade individual de produzir textos.

Para Bronckart (2006, p. 145), é preciso considerar as “condições de produção dos textos,” é preciso criar situações que provoquem um posicionamento do aluno com base nas suas leituras para que sua escrita não corra o risco de “dizer nada a ninguém, por nenhuma razão em particular” (BAZERMAN, 2006, 15). Para dizer algo é preciso ser capaz de articular o discurso, isso implica ser capaz de desenvolver capacidades referentes à intertextualidade, tanto na escrita, quanto na leitura, pois é na escrita que percebemos o quanto, como e o que o aluno lê.

Na resenha crítica, a intertextualidade é um aspecto crucial. Para Lima-Silva (2011, p. 05):

\begin{abstract}
Ela deve ser entendida em sua relação com os parâmetros de ação e com as operações mobilizadas na produção de resenhas, sobretudo no tocante à função que ela possui nesse gênero e como estratégia pela qual o estudante demonstra a interação com textos que lê e com o gênero que produz. Atividades de retextualização de textos teóricos provavelmente desafiam o aluno a mobilizar várias habilidades relacionadas à construção da intertextualidade, e é através do desafio de textualizar o diálogo com o texto fonte que o aluno pode desenvolver-se como produtor de resenhas.
\end{abstract}

Diante de tudo isso, é importante que não só os alunos, mas principalmente esses, quando solicitados a escrever algo ou algum gênero, sempre se perguntem sobre como dizer o que precisa comunicar e mais do que isso, se perguntem sobre como é a estrutura e o estilo da linguagem utilizada no gênero a que se propõe a escrever, qual é o domínio mínimo necessário para que os objetivos sejam alcançados.

Ainda que o saber sobre as estruturas não garanta o sucesso do resultado final, ele se mostra relevante nas operações discursivas, assim como são importantes as ações linguísticodiscursivas com o intuito de adequar-se aos parâmetros de ação de linguagem estabelecidos para as produções textuais em contextos específicos (MACHADO, 2005).

Enfim, é preciso que o aluno ou resenhista aproprie-se dos conceitos e procedimentos acadêmicos e científicos para saber fazer e saber dizer o que é preciso ser dito em cada contexto e em cada situação de interação, para que se torne um participante ativo na trajetória de formação acadêmica.

\title{
Referencias
}


ASKEHAVE, I.; SWALES, J. M. Identificação de gênero e propósito comunicativo: um problema e uma possível solução. In: BEZERRA, B. G.; BIASI-RODRIGUES, B.; CAVALCANTE, M. C. (Org.). Gêneros e sequências textuais. Recife: Edupe, 2009 [2001]. p. 221-247

BAZERMAN, C. Escrita, Gênero e Interação Social. Cortez, São Paulo. 2007.

BAZERMAN, C.. Os textos de alunos como índices para avaliação das capacidades de linguagem. In: MARI, H. et alli. Análise do Discurso em perspectivas. Belo Horizonte: FALE/UFMG, 2003, p. 215-229.

BOTELHO Laura Silveira. COSSON, Rildo, Letramento literário: teoria e prática. São Paulo: Editora Contexto, 2009. Disponível em: $<$ http://www.ufjf.br/fale/files/2010/06/Letramento-liter\%C3\%A1rio.pdf $>$. Acesso em 19 jul. 12.

ESMA. EDU. Normas para a elaboração de uma resenha. Disponível em: $<$ http://www.esma.edu.br/downloads/normas/Normas_resenha_esma.pdf $>$. Acesso em 19 jul. 2012.

INFOESCOLA. Como elaborar uma resenha crítica. Disponível em: $<$ http://www.infoescola.com/redacao/resenha-critica/>. 2012. Acesso 11 de jul. de 2012.

LIMA-SILVA. A Produção de Resenha Acadêmica no Ensino Superior. ReVeLe - ${ }^{0} 2$ Jan/2011. FALE/UFMG

MACHADO, A. R. A perspectiva sociodiscursiva de Bronckart. In: MEURER, J. L. et al; (Org.). Gêneros: teorias, métodos, debates. São Paulo: Parábola, 2005, p. 237-259.

MARCONI, M. A.; LAKATOS, E. M. Fundamentos de Metodologia Científica. 5. ed. São Paulo: Atlas. 2003.

MORAES Michele Adriana de. Resenha Sobre "Educação após Auschwitz" de ADORNO, Theodor W, (2003). Cadernos da Pedagogia. Ano 03, v. 01, n. 05, Janeiro / Jul. 2009. Disponível em: $<$ http://www.cadernosdapedagogia.ufscar.br/index.php/cp/article/viewFile/126/77>. Acesso em 19 jul. 2012.

MUNERATO, Camila. SANTOS Camila Rodrigues dos. CARDOSO Eunice Pereira Resenha de MORETTO, Vasco Pedro. Prova: Um momento privilegiado de estudo, não um acerto de contas. 2.ed. Rio de Janeiro: Lamparina, 2007. Disponível em: $<$ http://www.semar.edu.br/revista/pdf_ed3/resenha_revista.pdf $>$. Acesso em 19 jul. 12.

PUCRS. Guia de Produção de Texto Definição de Resenha Crítica. Disponível em: $<$ http://www.pucrs.br/gpt/resenha.php>. Acesso 11 jul. 2012.

FERNANDES. Requisitos básicos para um resenhista. RECANTO DAS LETRAS. Disponível em: <http://www.recantodasletras.com.br/teorialiteraria/596099>. Acesso 11 jul. 2012. 
FERNANDES. Modelo de Resenha Crítica. RECANTO DAS LETRAS. Disponível em: $<$ http://www.recantodasletras.com.br/artigos/1549258>. Acesso 11 jul.2012.

SCHNEUWLY, B. Gêneros e tipos de discurso: considerações psicológicas e ontogenéticas. In: SCHNEUWLY; B.; DOLZ, J. Gêneros orais e escritos na escola. Campinas: Mercado de Letras, 2004, p. 21- 39.

TOLEDO, Cezar de Alencar Arnaut de. BARBOZA Marcos Ayres. Resenha de: RATKE, Wolfgang. Escritos sobre A Nova Arte de Ensinar de Wolfgang Ratke (1571-1635): textos escolhidos. Apresentação, tradução e notas de Sandino Hoff. Campinas: Autores Associados, 2008.2 233p. Disponível em: <http://www.histedbr.fae.unicamp.br/revista/edicoes/34/res04_34.pdf $>$. Acesso em 19 jul. 2012. 